\title{
Conduction disorders after tricuspid annuloplasty with mitral valve surgery: Implications for earlier tricuspid intervention
}

\author{
Jérôme Jouan, MD, ${ }^{\mathrm{a}, \mathrm{b}}$ Alessandro Mele, MD, ${ }^{\mathrm{a}}$ Emmanuelle Florens, MD, ${ }^{\mathrm{a}, \mathrm{b}}$ Gilles Chatellier, MD, PhD, ${ }^{\mathrm{b}, \mathrm{c}}$
} Alain Carpentier, MD, PhD, ${ }^{\mathrm{a}, \mathrm{b}}$ Paul Achouh, MD, PhD, ${ }^{\mathrm{a}, \mathrm{b}}$ and Jean-Noël Fabiani, MD ${ }^{\mathrm{a}, \mathrm{b}}$

\begin{abstract}
Objective: Tricuspid valve repair has been recently advocated in patients undergoing mitral valve surgery who have mild to moderate secondary tricuspid regurgitation. However, the incidence of heart conduction disorders after combined mitral valve and tricuspid valve interventions has not been evaluated. We sought to analyze the incidence of permanent pacemaker implantations and heart conduction disorders in patients undergoing mitral valve surgery with and without tricuspid valve annuloplasty.
\end{abstract}

Methods: In 2011 and 2012, among 201 consecutive patients referred to the Hôpital Européen Georges Pompidou for isolated nonischemic mitral valve disease, 113 underwent an isolated mitral valve procedure (group 1) and 88 had a concomitant tricuspid valve ring annuloplasty (group 2).

Results: Patients' mean age was $59.7 \pm 16.5$ years in group 1 and $60.7 \pm 14.9$ years in group $2(P=.5)$. Mean crossclamp time and bypass time were $78 \pm 35$ minutes and $105 \pm 47$ minutes in group 1 and $92 \pm 36$ minutes and $128 \pm 50$ minutes in group 2 , respectively $(P=.001$ and .005 , respectively). Operative mortality was 3\% $(2.7 \%$ in group 1 and $3.2 \%$ in group $2, P=.4$ ). Incidence of high-grade heart conduction disorders lasting more than 3 days postoperatively was $14.5 \%$ in group 1 and $41.2 \%$ in group $2(P=.001)$. At 3 years, freedom from permanent pacemaker implantation was $99 \% \pm 2 \%$ in group 1 and $94.1 \% \pm 5 \%$ in group $2(P=.02)$. For the entire cohort, longer crossclamp time $(P=.02)$ and tricuspid ring annuloplasty (hazard ratio, 3.8; $P=.001$ ) were independent predictors of heart conduction disorders.

Conclusions: The need for permanent pacemaker implantation is increased after concomitant tricuspid ring annuloplasty in the setting of mitral valve surgery. A clinical period of observation up to 14 days after postoperative heart conduction disorders should be observed before recommending permanent pacemaker placement. (J Thorac Cardiovasc Surg 2016;151:99-103)

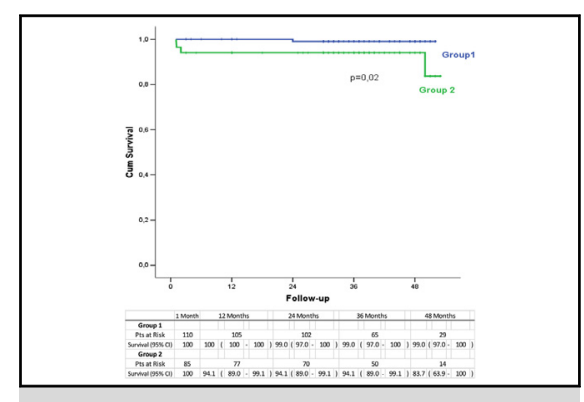

Freedom from permanent pacemaker implantation.

Central Message

In MV surgery, the risk for permanent pacemaker requirement was increased after concomitant tricuspid annuloplasty.

\section{Perspective}

The risk for permanent pacemaker implantation after combined MV surgery and prophylactic tricuspid ring annuloplasty is increased but remains overweighed by the hazard of developing late secondary TR.

See Editorial Commentary page 104.

See Editorial page 7.
Secondary tricuspid regurgitation (TR) is due to annular dilatation and leaflet tethering in relation to pressure or volume overload of the right chambers. Right ventricular

\footnotetext{
From the assistance Publique-Hôpitaux de Paris, Hôpital Européen Georges Pompidou, Département de Chirurgie Cardio-vasculaire, Paris, France; ${ }^{b}$ Université Paris-Descartes, Faculté de Médecine, Paris, France; and ${ }^{\mathrm{c}}$ Assistance Publique-Hôpitaux de Paris, Hôpital Européen Georges Pompidou, Département d'Epidémiologie et de Recherche Clinique, Paris, France.

Received for publication May 7, 2015; revisions received Aug 21, 2015; accepted for publication Sept 5, 2015.

Address for reprints: Jérôme Jouan, MD, Département de Chirurgie cardiovasculaire, Hôpital Européen Georges Pompidou, 20, rue Leblanc, 75015 Paris (E-mail: jouanjerome@ @otmail.com).

$0022-5223 / \$ 36.00$

Copyright (c) 2016 by The American Association for Thoracic Surgery http://dx.doi.org/10.1016/j.jtcvs.2015.09.063
}

pressure overload is mainly seen in pulmonary hypertension resulting from left-sided valve diseases. However, the reduction of TR after surgical correction of the left-sided lesion may be incomplete. ${ }^{1}$ Secondary TR may develop after successful left heart valve correction, leading to progressive heart failure and death. ${ }^{2}$ Subsequent surgical corrections of late isolated functional TR carry a high surgical risk and poor long-term prognosis. ${ }^{3}$ Thus, concomitant tricuspid valve (TV) annuloplasty has been proposed in cases of annular dilatation independently of the severity of TR. ${ }^{4,5}$ Nevertheless, the impact on postoperative complications of this aggressive approach has not been evaluated in the literature. In this regard, many authors have demonstrated that combined valve 


$$
\begin{aligned}
& \text { Abbreviations and Acronyms } \\
& \begin{aligned}
\mathrm{CI} & =\text { confidence interval } \\
\mathrm{MV} & =\text { mitral valve } \\
\mathrm{POD} & =\text { postoperative day } \\
\mathrm{TR} & =\text { tricuspid regurgitation } \\
\mathrm{TV} & =\text { tricuspid valve }
\end{aligned}
\end{aligned}
$$

operations are correlated with increased rate of permanent pacemaker implantations. ${ }^{6}$ However, although heart conduction disorder represents a classic complication of tricuspid ring annuloplasty, the specific risk of pacemaker implantation after concomitant TV annuloplasty is not well known. Therefore, we sought to evaluate the incidence and consequences of postoperative heart conduction disorders after combined mitral valve (MV) surgery and TV annuloplasty compared with isolated MV intervention.

\section{PATIENTS AND METHODS}

Between January 2011 and December 2012, we identified 201 consecutive adult patients who underwent nonemergency MV surgery for nonischemic disease. Of these, 113 underwent isolated MV surgery (group 1) and 88 had a concomitant TV annuloplasty performed using a Carpentier-Edwards Classic ring or Physio ring (group 2) (Edwards Lifesciences, Irvine, Calif). Patients who underwent additional procedures, such as aortic valve surgery, septal defect closure, or septal resection, and patients who preoperatively had a permanent pacemaker or second-degree or greater atrioventricular block were excluded. All surgeries were performed via median sternotomy using cardiopulmonary bypass and cardiac arrest. Tricuspid annuloplasty was performed under aortic crossclamping or heart-beating conditions depending on the surgeon's preference. The myocardial preservation technique was also at the discretion of surgeons, who used crystalloid or warm blood and antegrade or retrograde cardioplegia. In-hospital data were collected retrospectively from medical records. Follow-up was performed by direct phone contact with each patient and the referring cardiologist. The study was approved by our local ethics committee, and informed consent was obtained for all patients.

\footnotetext{
Statistical Analysis

Data analyses were performed with SPSS software (SPSS Inc, Chicago, III) and SAS software (SAS Institute Inc, Cary, NC). Descriptive statistics are expressed as mean \pm standard deviation or $95 \%$ confidence interval (CI) for continuous variables and percentage or frequencies for categoric variables. Daily postoperative electrocardiograms were reviewed by 2 physicians to identify heart conduction disorders and sinus node dysfunction. The primary clinical end point was defined as the implantation of a permanent pacemaker at any time during the follow-up period. The secondary end point included high-grade heart conduction disorders and sinus node dysfunction persisting 3 days postoperatively among survivors. High-grade heart conduction disorders were defined as second- and third-degree atrioventricular block. To identify significant differences in baseline characteristics and intraoperative variables as in clinical end points, groups 1 and 2 were compared using a chi-square or Fisher exact test for categoric data and Student $t$ test for continuous data. Comparisons between groups for freedom from permanent pacemaker implantation (primary clinical end point) were made by using the Kaplan-Meier method.
}

By considering the total study cohort, data were entered into a binary logistic regression analysis to highlight independent predictors for the secondary clinical end point. The appropriateness of tested variables was first determined by univariate analysis using a chi-square or Fisher exact test for categoric data and Student $t$ test for continuous data with a $P$ value less than .2.

\section{RESULTS}

In group 2, indications for concomitant TV annuloplasty were moderate to severe TR in $31.8 \%(\mathrm{n}=28)$ and prophylactic (defined as annular dilatation associated with mild or less TR) in 68.2\% $(\mathrm{n}=60)$. Baseline and intraoperative characteristics of the 2 groups are summarized in Table 1. Concomitant TV procedure was done under cardioplegic cardiac arrest in $85.2 \%(\mathrm{n}=75)$ and on the beating heart in $14.8 \%(\mathrm{n}=13)$. Postoperative data are described in Table 2. Mean hospital length of stay was significantly increased in group 2 compared with group 1: 16 days $(95 \% \mathrm{CI}, 14.1-17.8)$ and 12.6 days (95\% CI, 10.6-14.5), respectively $(P=.01)$. Overall operative mortality was $3 \%(\mathrm{n}=6): 3.4 \%$ in group 2 and $2.7 \%$ in group $1(P=.53)$. There were also 2 late deaths during follow-up at 10 and 12 months, 1 in each group, but neither was related to heart conduction disorder. Mean follow-up was $36 \pm 12$ months.

\section{Primary Clinical End Point}

Among operative survivors, early permanent pacemaker implantations ( $<3$ months) were performed in 5 patients. Two patients required late permanent pacemaker implantation at 24 and 48 months. At 36 months, freedom from permanent pacemaker was $94.1 \%$ (95\% CI, 87-99) for group 2 compared with $99 \%(95 \% \mathrm{CI}, 97-100)$ for group $1(P=.02)$ (Figure 1). Indications for pacemaker implantation were third-degree atrioventricular blocks in all but 1 patient, who presented with sinus node dysfunction.

\section{Secondary Clinical End Point}

A total of 51 patients $(26.1 \%)$ experienced a secondary clinical end point. Patients in group 2 had significantly more persistent postoperative high-grade heart conduction disorders than patients in group $1(41.2 \%$ and $14.5 \%$, respectively, $P<.01)$. Beating heart conditions during TV annuloplasty in group 2 were not associated with less occurrence of the secondary clinical end point $(P=.51)$. Conduction recovery was obtained before postoperative day (POD) 7 in 42 patients. Among the remaining patients, 4 additional recoveries from high-grade to lower-grade heart conduction disorders or restorations to normal conduction patterns were observed up to POD 21. For the whole cohort, TV annuloplasty and longer crossclamp 
TABLE 1. Baseline and intraoperative characteristics of the study population

\begin{tabular}{|c|c|c|c|c|c|c|c|c|c|c|}
\hline & \multicolumn{3}{|c|}{ Total $(n=202)$} & \multicolumn{3}{|c|}{ Group $1(n=113)$} & \multicolumn{3}{|c|}{ Group $2(\mathbf{n}=\mathbf{8 8})$} & \multirow[b]{2}{*}{$P$ value } \\
\hline & Mean \pm SD & $\mathbf{N}$ & $\%$ & Mean \pm SD & $\mathbf{N}$ & $\%$ & Mean \pm SD & $\mathbf{N}$ & $\%$ & \\
\hline Age $(y)$ & $60.2 \pm 15.8$ & & & $59.7 \pm 16.5$ & & & $60.7 \pm 14.9$ & & & .65 \\
\hline Female gender & & 90 & 44.8 & & 49 & 43.4 & & 41 & 46.6 & .64 \\
\hline Logistic euroSCORE II & $6.04 \pm 1.3$ & & & $5.9 \pm 2.0$ & & & $6.2 \pm 1.4$ & & & .81 \\
\hline Preoperative sPAP (mm Hg) & $45.9 \pm 16.6$ & & & $42.1 \pm 15.1$ & & & $51.0 \pm 17.1$ & & & $<.01$ \\
\hline Preoperative TR & & & & & & & & & & $<.01$ \\
\hline Trace to mild & & 166 & 82.6 & & 106 & 93.8 & & 60 & 69.3 & \\
\hline Moderate to severe & & 35 & 17.4 & & 7 & 6.2 & & 28 & 31.8 & \\
\hline \multicolumn{11}{|l|}{ Preoperative low-grade HCDs } \\
\hline First-degree AVB & & 19 & 9.5 & & 13 & 11.5 & & 6 & 6.8 & .24 \\
\hline RBBB & & 16 & 8.0 & & 5 & 4.4 & & 11 & 12.5 & .04 \\
\hline LBBB & & 9 & 4.5 & & 5 & 4.4 & & 4 & 4.5 & .62 \\
\hline Cause of MV disease & & & & & & & & & & .01 \\
\hline Degenerative & & 125 & 62.2 & & 74 & 65.5 & & 51 & 58.1 & \\
\hline Rheumatic & & 46 & 22.9 & & 20 & 17.7 & & 26 & 29.5 & \\
\hline PV dysfunction & & 13 & 6.5 & & 9 & 8 & & 4 & 4.5 & \\
\hline Endocarditis & & 9 & 4.5 & & 8 & 7.1 & & 1 & 1.1 & \\
\hline Others & & 8 & 4.0 & & 1 & 0.9 & & 6 & 6.8 & \\
\hline MV replacement & & 74 & 36.8 & & 41 & 36.3 & & 33 & 37.5 & .49 \\
\hline Bioprosthesis & & & & & 21 & 18.8 & & 21 & 23.9 & .11 \\
\hline Mechanical valve & & & & & 20 & 17.7 & & 12 & 13.6 & .40 \\
\hline CBP time (min) & $115 \pm 49$ & & & $105 \pm 47$ & & & $128 \pm 50$ & & & $<.01$ \\
\hline Crossclamp time (min) & $84 \pm 36$ & & & $78 \pm 35$ & & & $92 \pm 36$ & & & $<.01$ \\
\hline Associated Cox-Maze procedure & & 16 & 8.0 & & 7 & 6.2 & & 9 & 10.2 & .30 \\
\hline \multicolumn{11}{|l|}{ Cardioplegia } \\
\hline Crystalloid (vs warm blood) & & 141 & 70.1 & & 83 & 73.5 & & 58 & 65.9 & .25 \\
\hline Retrograde (vs antegrade) & & 31 & 15.4 & & 12 & 10.6 & & 19 & 21.6 & .03 \\
\hline No. of redo surgeries & & & & & & & & & & .07 \\
\hline 1 & & 35 & 17.4 & & 12 & 10.6 & 23 & & 26.1 & \\
\hline 2 & & 5 & 2.5 & & 4 & 3.5 & 1 & & 1.1 & \\
\hline$\geq 3$ & & 9 & 4.5 & & 6 & 5.3 & 3 & & 3.4 & \\
\hline
\end{tabular}

Cox Maze procedures were performed by pulmonary vein isolation using endocardial cryotherapy and left appendage surgical exclusion. SD, Standard deviation; euroSCORE, European System for Cardiac Operative Risk Evaluation; $s P A P$, systolic pulmonary pressure; $T R$, tricuspid regurgitation; $H C D$, heart conduction disorder; $A V B$, atrioventricular block; $R B B B$, right bundle branch block; $L B B B$, left bundle branch block; $M V$, mitral valve; $P V$, prosthetic valve; $C P B$, cardiopulmonary bypass.

time were associated with the occurrence of the secondary clinical end point. In multivariate analysis, these 2 factors were also independently related to the secondary clinical end point (Table 3).

\section{DISCUSSION}

TV annuloplasty is more frequently performed in association with MV interventions even in the absence of severe functional TR, as recommended by most recent international guidelines. We found that this concomitant approach carries a significantly increased risk of postoperative high-grade heart conduction disorders. However, the final rate of permanent pacemaker implantation at 3 years was approximately $6 \%$ in this population.

Several studies have evaluated the need for pacemakers after valve interventions. The rate of pacemaker

TABLE 2. Postoperative outcomes of the study population

\begin{tabular}{|c|c|c|c|c|c|c|c|c|c|c|c|c|c|}
\hline & \multicolumn{4}{|c|}{ Total $(n=202)$} & \multicolumn{4}{|c|}{ Group $1(n=113)$} & \multicolumn{4}{|c|}{ Group $2(\mathbf{n}=\mathbf{8 8})$} & \multirow[b]{2}{*}{$P$ value } \\
\hline & Mean & $95 \%$ CI & $\mathbf{N}$ & $\%$ & Mean & $95 \% \mathrm{CI}$ & $\mathbf{N}$ & $\%$ & Mean & $95 \% \mathrm{CI}$ & $\mathbf{N}$ & $\%$ & \\
\hline Mean ICU length of stay & 4.3 & $3.4-5.3$ & & & 4.2 & $2.7-5.7$ & & & 4.6 & $3.5-5.6$ & & & .68 \\
\hline Total hospital length of stay & 14.1 & $12.7-15.4$ & & & 12.6 & $10.6-14.5$ & & & 16 & $14.1-17.8$ & & & .01 \\
\hline LCOS & & & 14 & 7.0 & & & 8 & 7.1 & & & 6 & 6.8 & .58 \\
\hline In-hospital death & & & 6 & 3.0 & & & 3 & 2.7 & & & 3 & 3.4 & .35 \\
\hline High-grade conduction disorders $>3$ days* & & & 51 & 26.2 & & & 16 & 14.5 & & & 35 & 41.2 & $<.01$ \\
\hline
\end{tabular}




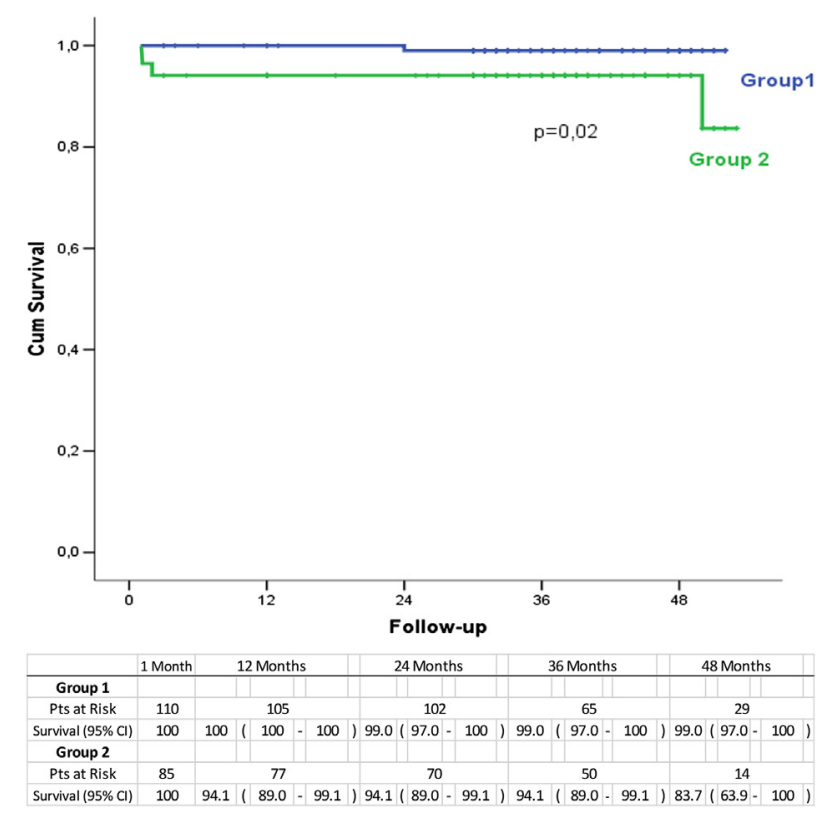

FIGURE 1. Freedom from permanent pacemaker implantation. $C I$, Confidence interval.

implantation after TV replacement seems to be higher than after other valve interventions. ${ }^{7,8} \mathrm{TV}$ repairs also have been implicated in postoperative heart conduction disorders. Our data confirmed these results because no permanent pacemaker was implanted in the immediate postoperative course of patients with isolated MV intervention. However, we cannot exclude that this might have been related to the relatively small sample size of our study. In a previous report from our group, we found a $2.6 \%$ incidence of pacemaker implantation after isolated MV repair. ${ }^{9}$ Jokinen and colleagues ${ }^{10}$ recently reported a $21 \%$ incidence of pacemaker implantation after TV operations that were mostly ring annuloplasties. In their study, the use of complete prosthetic rings instead of open rings was advocated. Indeed, the anatomic proximity of $\mathrm{TV}$ annular septal segment to the atrioventricular node increased the risk of damage to the latter during TV interventions. To avoid any detrimental stitch placement, some surgeons prefer to operate

TABLE 3. Multivariate predictors for the secondary clinical end point

\begin{tabular}{lllrc}
\hline & HR & \multicolumn{2}{c}{$\mathbf{9 5} \%$ CI } & $P$ value \\
\hline Age & 1.02 & 0.99 & 1.04 & .15 \\
Female gender & 1.56 & 0.75 & 3.23 & .18 \\
Preoperative LBBB & 2.71 & 0.63 & 11.60 & .18 \\
TV annuloplasty & 3.81 & 1.87 & 7.79 & $<.01$ \\
Crossclamp time & 1.01 & 1.00 & 1.02 & .02 \\
\hline
\end{tabular}

HR, Hazard ratio; $C I$, confidence interval; $L B B B$, left bundle branch block; $T V$, tricuspid valve. under beating-heart conditions during TV procedures. In the present study, we did not find any difference in clinical end points related to the surgical technique used during TV annuloplasty.

In the study by Jokinen and colleagues, ${ }^{10}$ the high rate of postoperative pacemaker requirement also could be explained by the fact that the decision for implantation was made quickly during the postoperative course, as early as POD 5. Our strategy regarding postoperative heart conduction disorders was different. In our series, most of the recoveries were observed before POD 7, but half of the patients who had high-grade heart conduction disorders beyond this limit did not finally require permanent pacemaker placement. We admit that an increase in the clinical period of observation after cardiac surgery might have a significant impact on cost-benefit considerations and delay a patient's discharge to rehabilitation. That cost needs to be weighed against the cost of pacemaker implantation, its regular clinical controls, and its potential complications. Pacemaker implantation itself increases the risk of endocarditis and thromboembolic complications and impairs quality of life. ${ }^{10}$ Furthermore, some studies suggest that one third to one half of patients who received permanent pacing after cardiac surgery will ultimately be pacemaker-nondependent. ${ }^{11,12}$

Identification of preoperative predictors may help in the decision-making process and optimal timing of postoperative permanent pacemaker requirement. Koplan and colleagues $^{13}$ have proposed a risk score incorporating different preoperative and intraoperative parameters, such as age, prior valve surgery, and surgery type. Other studies have also identified female gender, body mass index, history of syncope, preoperative left bundle branch block, and longer bypass time as predictors of permanent pacing after valve surgery. ${ }^{14}$ In our multivariate analysis of the total study cohort, we could only confirm that crossclamping time was, along with TV ring annuloplasty, an independent factor for postoperative high-grade heart conduction disorders. This should be partially explained by the intrinsic properties of the atrioventricular conduction tissue, which has a lesser protective effect against ischemia during hyperkalemic or hypothermic cardiac arrest. ${ }^{15}$

\section{Study Limitations}

This study is subject to limitations inherent to a retrospective analysis of observational data and small sample size. Operative deaths were not included in clinical end points, although these patients might have presented high-grade heart conduction disorders. However, it was impossible to know if a normal conduction pattern would have been eventually restored. 
Groups 1 and 2 differed at baseline regarding preoperative right heart disease, right bundle branch block, and cause of MV disease and intraoperatively by crossclamp time and technique of myocardial preservation. Nevertheless, we conducted a logistic regression analysis of the whole study cohort and found that tricuspid ring annuloplasty was an independent risk factor for the secondary clinical end point. A Cox multivariate analysis on the entire cohort with regard to the primary clinical end point was not similarly performed because of the small incidence of pacemaker implantations.

\section{CONCLUSIONS}

Performance of an associate tricuspid ring annuloplasty during MV surgery increases the risk of early and late conduction disturbance and need for pacemaker implantation. This finding should be taken into consideration in the decision to address preventively tricuspid annular dilatation and balanced with the risk for potential development of late secondary TR.

\section{Conflict of Interest Statement}

Dr Carpentier reports grants from Ewards Lifesciences, outside the submitted work. In addition, Dr Carpentier has a patent Carpentier Edwards Tricuspid Classic and Physio Ring with royalties paid. All other authors have nothing to disclose with regard to commercial support.

\section{References}

1. Desai RR, Vargas Abello LM, Klein AL, Marwick TH, Krasuski RA, Ye Y, et al. Tricuspid regurgitation and right ventricular function after mitral valve surgery with or without concomitant tricuspid valve procedure. J Thorac Cardiovasc Surg. 2013;146:1126-32.e10.

2. Porter A, Shapira Y, Wurzel M, Sulkes J, Vaturi M, Adler Y, et al. Tricuspid regurgitation late after mitral valve replacement: clinical and echocardiographic evaluation. J Heart Valve Dis. 1999;8:57-62.
3. Pfannmüller B, Moz M, Misfeld M, Borger MA, Funkat A-K, Garbade J, et al. Isolated tricuspid valve surgery in patients with previous cardiac surgery. J Thorac Cardiovasc Surg. 2013;146:841-7.

4. Dreyfus GD, Corbi PJ, Chan KMJ, Bahrami T. Secondary tricuspid regurgitation or dilatation: which should be the criteria for surgical repair? Ann Thorac Surg. 2005;79:127-32.

5. Nishimura RA, Otto CM, Bonow RO, Carabello BA, Erwin JP, Guyton RA, et al. 2014 AHA/ACC guideline for the management of patients with valvular heart disease: a report of the American College of Cardiology/American Heart Association Task Force on Practice Guidelines. J Thorac Cardiovasc Surg. 2014;148:e1-132.

6. Goldman BS, Hill TJ, Weisel RD, Scully HE, Mickleborough LL, Pym J, et al. Permanent cardiac pacing after open-heart surgery: acquired heart disease. Pacing Clin Electrophysiol. 1984;7(3 Pt 1):367-71.

7. Scully HE, Armstrong CS. Tricuspid valve replacement. Fifteen years of experience with mechanical prostheses and bioprostheses. J Thorac Cardiovasc Surg. 1995;109:1035-41

8. Do QB, Pellerin M, Carrier M, Cartier R, Hébert Y, Pagé P, et al. Clinical outcome after isolated tricuspid valve replacement: 20-year experience. Can J Cardiol. 2000;16:489-93.

9. Meimoun P, Zeghdi R, D'Attelis N, Berrebi A, Braunberger E, Deloche A, et al. Frequency, predictors, and consequences of atrioventricular block after mitral valve repair. Am J Cardiol. 2002;89:1062-6.

10. Jokinen JJ, Turpeinen AK, Pitkänen O, Hippeläinen MJ, Hartikainen JEK Pacemaker therapy after tricuspid valve operations: implications on mortality, morbidity, and quality of life. Ann Thorac Surg. 2009;87:1806-14.

11. Batra AS, Wells WJ, Hinoki KW, Stanton RA, Silka MJ. Late recovery of atrioventricular conduction after pacemaker implantation for complete heart block associated with surgery for congenital heart disease. J Thorac Cardiovasc Surg. 2003;125:1291-3.

12. Onalan O, Crystal A, Lashevsky I, Khalameizer V, Lau C, Goldman B, et al. Determinants of pacemaker dependency after coronary and/or mitral or aortic valve surgery with long-term follow-up. Am J Cardiol. 2008;101: 203-8.

13. Koplan BA, Stevenson WG, Epstein LM, Aranki SF, Maisel WH Development and validation of a simple risk score to predict the need for permanent pacing after cardiac valve surgery. J Am Coll Cardiol. 2003;41: 795-801.

14. Erdogan HB, Kayalar N, Ardal H, Omeroglu SN, Kirali K, Guler M, et al. Risk factors for requirement of permanent pacemaker implantation after aortic valve replacement. J Card Surg. 2006;21:211-7.

15. Tchervenkov CI, Wynands JE, Symes JF, Malcolm ID, Dobell AR, Morin JE. Electrical behavior of the heart following high-potassium cardioplegia. Ann Thorac Surg. 1983;36:314-9.

Key Words: conduction disorders, tricuspid valve annuloplasty, mitral valve surgery 